$\mathcal{G}_{\text {http://dx.doi.org/10.3765/sp.6.4 }}^{\text {Semantics \& Pragmatics Volume 6, Article 4: 1-44, } 2013}$

\title{
'And' or 'or': General use coordination in ASL*
}

\author{
Kathryn Davidson \\ Yale University
}

Submitted 2012-08-31 / Accepted 2012-10-21 / Revisions received 2012-12-10 / Revisions requested 2013-01-21 / Final version received 2013-03-18 / Published 2013-08-09

\begin{abstract}
In American Sign Language (ASL), conjunction ('and') and disjunction ('or') are often conveyed by the same general use coordinator (transcribed as "COORD"). So the sequence of signs MARY WANT TEA COORD COFFEE can be interpreted as 'Mary wants tea or coffee' or 'Mary wants tea and coffee' depending on contextual, prosodic, or other lexical cues. This paper takes the first steps in describing the syntax and semantics of two general use coordinators in ASL, finding that they have a similar syntactic distribution to English coordinators and and or. Semantically, arguments are made against an ambiguity approach to account for the conjunctive and disjunctive readings; instead, I propose a Hamblin-style alternative semantics where the disjunctive and conjunctive force comes from external quantification over a set of alternatives. The pragmatic consequences of using only a prosodic distinction between disjunction from conjunction is examined via a felicity judgement study of scalar implicatures. Results indicate decreased scalar implicatures when COORD is used as disjunction, supporting the semantic analysis and suggesting that the contrast of lexical items in the 〈and, or scale plays an important role in its pragmatics. Extensions to other languages with potential general use coordination are discussed.
\end{abstract}

Keywords: conjunction, disjunction, experimental pragmatics, coordination, sign languages, external quantification, alternatives, scalar implicatures

* Many people provided valuable contributions to this work: thanks to Marla Hatrak, Doreen Simons, Laura Levesque, and Sherry Powell for their expert ASL consultation, Cami Miner and Corinne Brion for assistance in creating stimuli, and to Carol Padden, Brandon Scates, Philippe Schlenker, Diane Lillo-Martin, Kazumi Matsuoka, Klinton Bicknell, and three reviewers for helpful suggestions and data. Insights from discussions with Ivano Caponigro, Rachel Mayberry, and Scott AnderBois helped guide this paper to its current state. Thanks also to audiences at the meetings of the 2012 LSA and the 2011 Amsterdam Colloquium, where an earlier stage of this work appeared.

(C)2013 Kathryn Davidson

This is an open-access article distributed under the terms of a Creative Commons NonCommercial License (creativecommons.org/licenses/by-nc/3.o). 


\section{Introduction}

In “Aristotle Goes to Arizona and Finds a Language without 'And”', Gil 1991 describes the strategy of conjunction and disjunction used in Maricopa (a Yuman language), which involves simple juxtaposition. In (1a) the verb is marked with the plain future tense, in contrast to the sentence in (1b), where the verb includes a modal/evidential element that conveys uncertainty. Consequently, (1a) is interpreted conjunctively while (1b) is interpreted disjunctively, even though in both cases the NP coordinates are simply juxtaposed.

(1) a. John-s Bill-s v?aawuum.

John-NOM Bill-NOM 3.come.PL.FUT

'John and Bill will come.'

b. John-s Bill-s v?aawuumsaa.

John-NOM Bill-NOM 3.come.PL.FUT.INFER

'John or Bill will come.'

Ohori 2004 describes a similar pattern in Japanese. When the typically overt conjunctive to (on each coordinate) and disjunctive $k a$ (on each coordinate) are omitted, the interpretation is inferred from the context (2).

(2) a. Doko-ni ikatai no?

Where-DAT go.vOL PRT

'Where do you wish to go?'

Kyoto, Nara, Kobe, da na

Kyoto, Nara, Kobe, cOP PRT

'Kyoto, Nara, and Kobe, I suppose'

b. Doko-ni sumitai no?

Where-DAT live.vOL PRT

'Where do you wish to live?'

Kyoto, Nara, Kobe, da na

Kyoto, Nara, Kobe, COP PRT

'Kyoto, Nara, or Kobe, I suppose'

This paper investigates conjunction and disjunction in American Sign Language (ASL), where a "general use coordinator" (“COORD”) can be interpreted as conjunction (3a) or as disjunction (3b).

1 Manual signs are transcribed in small capital letter glosses with rough English translation 
'And' or 'or'

(3) a. Context: I know that everyone had exactly one drink at the party. I wonder what Mary chose to drink at the party, and ask my friend. She replies:

IX Mary DRINK TEA coord COFFEE.

'She (Mary) drank tea or coffee.'

b. Context: I see that Mary looks very caffeinated and sick! I wonder how much caffeine she may have had, and ask my friend. She replies: IX Mary DRINK TEA coord COFFEE!

'She (Mary) drank tea and coffee!'

Like the modal/evidential element in Maricopa, or the change of context in Japanese, various factors affect interpretation of the general use coordination in ASL. These include a change in context (3), different nonmanual/intonational marking, the addition of discourse particles like EITHER and вотн, and different morphological marking on anaphora that co-refer with the coordinates. The main purpose of this paper is to (i) better understand general use coordination by making a case study of ASL; (ii) provide a semantic analysis using mechanisms suggested for independent reasons that can account for the pattern in ASL and can potentially be extended to the examples seen in Maricopa and Japanese; and (iii) investigate the pragmatic consequences of using general use coordination as opposed to using lexically contrastive coordinators like English and and or.

Within sign language research, previous studies on coordination focused on differentiating coordinate from subordinate structures (Padden 1988, Liddell 1980, van Gijn 2004) and on the use of coordinating constructions for various purposes (Fischer \& Lillo-Martin 1990, Waters \& Sutton-Spence 2005, Vermeerbergen, Leeson \& Crasborn 2007, Johnston \& Schlembri 2007). Surprisingly, there has been little mention of the specific syntactic and semantic properties of different forms of conjunction and disjunction in ASL. This is supported by the most extensive typological study of coordination to date in Haspelmath 2004, which included languages from Africa, the Caucasus, the Middle East, Southeast Asia, the Pacific, and the Americas, but no sign language data. Section 2 describes the syntactic distribution of two different general use coordinators in ASL, showing that they pattern similarly syntactically to English and and or in coordinating NPs, VPs, and clauses, and in using the same forms of disjunction for both declarative and interrogative

equivalents. IX stands for an indexical point, which can function as a pronoun, and subscripts indicate referents via loci. 
clauses.

Section 3 provides several arguments for not separating the disjunctive and conjunctive uses of these coordinators as two separate lexical items (i.e. a true ambiguity). Instead, I propose that a general use coordinator creates with its coordinates a set of alternatives, and these alternatives follow combinatorial rules outlined by Hamblin 1973 for questions. The specific implementation is based on Alonso-Ovalle's (2006) analysis of disjunction, and fits within a larger framework of alternative semantics where the "force" of the coordinator, i.e. whether all coordinates or at least one coordinate must be true, comes from outside the disjunctive phrase (Simons 2005, Groenendijk 2009, Groenendijk \& Roelofsen 2009, AnderBois 2011) or conjunctive phrase (Winter 2007).

In the analysis proposed here, there is no lexical contrast between the disjunctive and conjunctive readings of general use coordination; instead, readings arise through the interaction of the coordinator with other pieces of the language. One question that emerges is whether this lack of a lexical contrast has pragmatic effects. This is of special relevance for conjunction and disjunction because important aspects of their meaning have been accounted for based on the contrasting set they create with other coordinators. A prominent example is the scalar implicature associated with disjunction, which gives rise to the "exclusive" ('A or B but not both') meaning by positing a basic "inclusive" ('A or B and maybe both') meaning. Since Grice 1989, the exclusive interpretation of $o r$ has been commonly attributed to a scalar implicature arising from the alternatives and and or ordered on a scale $\langle$ and, or $\rangle$. When a speaker chooses to say Mary drank tea or coffee, the stronger description Mary drank tea and coffee is assumed to be false (because if it were true, the speaker should have said that instead). Thus, Mary drank tea or coffee is taken to mean 'Mary drank tea or coffee but not both' (see also Gazdar 1979, Horn 1989).

There has been a great deal of research recently concerning where and how such implicatures arise, but it remains an open question exactly what kind of linguistic material can contribute to the creation of lexical scales like English $\langle a n d, o r\rangle$. Section 4 presents quantitative data from a small felicity judgment experiment where the conjunctive and disjunctive interpretations of general use coordination are distinguished only by non-manual marking, essentially the equivalent of intonation in spoken languages. Results show that this potential "scale" triggers fewer implicatures than lexically contrastive scales in both ASL and in English. Taken with the semantic analysis 
'And' or 'or'

presented in Section 3, these results suggest that general use coordinators are not comprised of separate lexical items, the conjunctive and the disjunctive coordinators. Instead, each general use coordinator appears to have a single underlying meaning, and information such as intonation serves not to differentiate two separate lexical items, but rather to aid in interpretation in the same way as, for example, context and discourse particles. Section 5 concludes and discusses extensions of this research to other languages.

\section{The distribution of various forms of coordination in ASL}

Native speakers of Japanese report that while Ohori's data (listing NPs without conjunction or disjunction) in (2) above is grammatical, it is somewhat restricted in use. A more common strategy for conveying the same information would be to use the overt disjunction $k a$ and conjunction to. Gil reports that Maricopa lacks an overt conjunction (like many languages, Haspelmath 2004, 2007), but does allow an overt disjunctive marker, although as we saw in (1) it is not required. ASL is unlike Japanese (and potentially Maricopa) in that general use coordination is a very common method of conveying conjunction or disjunction in the language. Most ASL-English dictionaries fail to address this fact: instead, they often provide ASL learners with different signs which can be translated as 'or' or 'and'. These signs are more rare, and will be briefly reviewed below after the more extensive discussion of the syntactic distribution of two forms of general use coordination.

Native ASL signer judgments were gathered for each coordinator in various sentence structures described below. The primary source consulted for each judgment was a profoundly deaf signer whose grandparents, parents, and husband are all deaf, and all use American Sign Language. She is knowledgeable about linguistics and grammaticality judgments but was naive to the goal of the present work during the consultation phase. Each judgment was also confirmed by at least one other deaf native signer (these signers varied in their linguistic background), and typically also a third deaf signer.

\subsection{General use coordinators}

In this section, I focus on the two general use coordinators found in ASL: COORD-L (Section 2.1.1) and COORD-SHIFT (Section 2.1.2). 


\subsubsection{COORD-L}

The first, which I label COORD-L, illustrated in Figure 1, consists of the signer's dominant hand pointing with a G ("index finger") or sometimes B ("flat closed hand") handshape to successive fingers on the non-dominant hand before each successive coordinate, beginning with either the thumb or the index finger. Possible number of fingers on the non-dominant hand range from two to all five fingers. This strategy of coordination has also been termed a List Buoy (Liddell 2003), possibly to convey the idea that the relationship between the coordinator and the coordinates can be thought of as one of support, where COORD-L "buoys" the coordination of the coordinates. Here, I transcribe a point to the $n$th finger on the non-dominant hand used for coordination as COORD- $\mathrm{L}_{n}$, where $1 \rightarrow$ thumb/index. It's important to note that while a COORDL precedes each coordinate, it's unlike either ... or in English because the first COORD-L is never optional, and also must immediately precede the first coordinate (compare to English John has either eaten [cake] or [icecream]). ${ }^{2}$

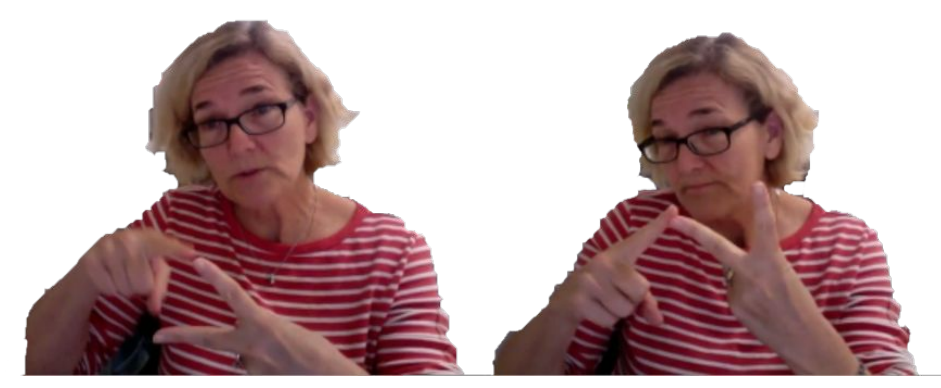

Figure 1 COORD-L: COORD-L $\mathrm{L}_{1}$ COORD-L 2

Disjunctive and conjunctive interpretations are disambiguated by various factors including the context, additional lexical material, or nonmanual marking, which consists of movements of the face and torso, and here especially the eyes and eyebrows that are roughly equivalent in function to intonation in spoken languages (Sandler 2012). ${ }^{3}$ In (4), ${ }^{4}$ the sentence containing the coordinator is followed by a partially elided clause (more specifically, a

2 Thanks to an anonymous reviewer for this point.

3 When nonmanual marking is not under investigation, I will not mark it in the example sentences. This is analogous to the convention in spoken languages, where intonation is typically not part of an annotation except when it is the object of discussion.

4 Poss 'possessive', like IX 'indexical/pronoun', is gender-neutral and singular (unless it 
'And' or 'or'

clause whose complement is an embedded sluiced constituent interrogative introduced by a D-linked $w h$-word). This clause is compatible only with a disjunctive interpretation of the preceding coordination phrase, which is also typically (though not obligatorily) signed with nonmanual marking specific to a disjunctive interpretation. On the other hand, the very open general question 'What will happen?', preceding the coordinator in (5) favors a conjunctive interpretation of the coordination phrase. With appropriate nonmanuals or followed by DON'T-KNOW WHICH 'I don't know which', the same string in (5) could also be interpreted as disjunction.

(4) COORD-L C $_{1}\left[\right.$ POSS $_{a}$ PARENTS WILL BUY POSS $a$ CAR] COORD-L CIX $_{a}$ WILL TRAVEL], DON'T-KNOW WHICH.

'Her parents will buy her car or she will travel, I'm not sure which.'

(5) HAPPEN? COORD-L ${ }_{1}\left[\right.$ POSS $_{a}$ PARENTS WILL BUY POSS $a$ CAR] COORD-L CIX $_{a}$ WIL TRAVEL].

'What will happen? Her parents will buy her car, and (then) she will travel.'

As disjunction, COORD-L can appear in many different sentence types, like English or. It can be used in alternative questions (6a) with appropriate nonmanual marking, in declarative statements that are interpreted exclusively, as seen in (4) and repeated below in (6b), and declarative statements interpreted inclusively, as illustrated by the addition of MAYBE BOTH (6c). There is no specific disjunction for asking alternative questions, as in Mandarin (Li \& Thompson 1981) or disjunction specific to declarative clauses, as in Kannada (Amritavalli 2003). Note that in each of these cases the linguistic additions (nonmanual marking for questions or lexical material in declarative statements) also serve to clarify that the coordination should be interpreted as disjunction, not conjunction.

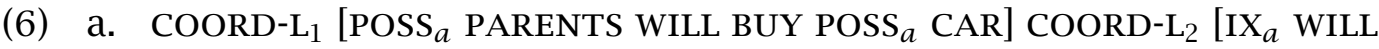
TRAVEL]?

'Will her parents buy her car or will she travel?' (Alternative question, possible answers: car, travel)

b. COORD-L L $_{1}\left[\right.$ POSS $_{a}$ PARENTS WILL BUY POSS $a$ CAR] COORD-L ${ }_{2}\left[\mathrm{IX}_{a}\right.$ WILL TRAVEL], (DON'T-KNOW WHICH)

involves the plural marker, an arc movement), and is associated with a location or "locus" in space, noted with subscripts. 
'Her parents will buy her car or she will travel, I'm not sure which.' (Exclusive Statement)

c. COORD-L L $_{1}\left[\right.$ POSS $_{a}$ PARENTS WILL BUY POSS $a$ CAR] COORD-L [IX $_{a}$ WILL TRAVEL], (MAYBE BOTH)

'Her parents will buy her car or she will travel, maybe both.' (Inclusive Statement)

COORD-L can also connect predicates in the same sentence types: alternative questions (7a), exclusive statements ( $7 \mathrm{~b})$, and inclusive statements (7c).

(7) a. MARY COORD-L $\mathrm{L}_{1}[\mathrm{SWIM}]$ COORD-L 2 [RUN]?

'Does Mary swim or run?'

(Alt. question, possible answers: swim, run)

b. MARY COORD-L $\mathrm{L}_{1}$ [SWIM] COORD-L2 [RUN], (DON'T-KNOW WHICH). 'Mary swims or runs, I'm not sure which.'

(Exclusive Statement)

C. MARY COORD-L 1 [SWIM] COORD-L 2 [RUN], (MAYBE BOTH).

'Mary swims or runs, and maybe both.'

(Inclusive Statement)

So far, in all cases the ASL sign COORD-L in its disjunctive interpretation exhibits a distribution similar to English or: it can be used to ask alternative questions, for exclusive statements and inclusive statements, and to connect both clauses and predicates/VPs. There appears to be one difference between the syntactic distribution of COORD-L and English or, and that is related to prosody and number of coordinates. For some (but not all) signers, the use of COORD-L is reported to feel too heavy prosodically to connect two small light nouns (8). It is, however, improved with the addition of a third coordinate.

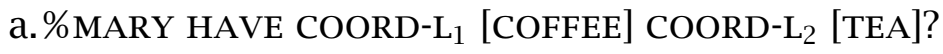

'Did Mary have coffee or tea?'

(Alt. question, can answer: coffee, tea)

b. MARY HAVE COORD- $\mathrm{L}_{1}$ [COFFEE] COORD- $\mathrm{L}_{2}$ [TEA] COORD- $\mathrm{L}_{3}$ [CHOCOLATE]?

'Did Mary have coffee, tea, or chocolate?'

(Alt. question, can answer: coffee, tea, chocolate)

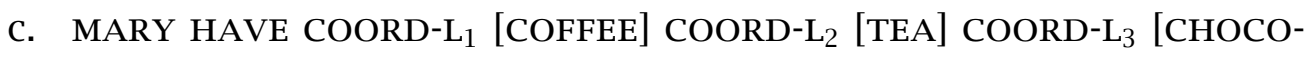
LATE] (DON'T-KNOW WHICH). 
'And' or 'or'

'Mary had coffee, tea, or chocolate, I'm not sure which.'

(Exclusive Statement)

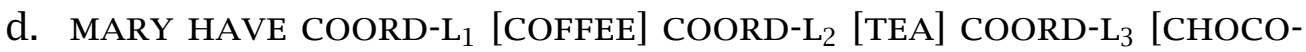
LATE], (MAYBE ALL).

'Mary had coffee, tea, chocolate, and maybe all.'

(Inclusive Statement)

COORD-L thus seems to share the syntactic and semantic properties of English coordinators, but with a preference towards use in longer lists when coordinates are prosodically light.

\subsubsection{COORD-shift}

A second possibly way to coordinate clauses, predicates, and nouns in ASL is to shift the body slightly (moving a combination of torso, head, and/or eyes) for each coordinated element, and sign each of the coordinated items in a separate locus in the signing space. Separate loci are notated by separate subscripts, and in COORD-SHIFT are typically the signer's left side and signer's right side, respectively, although they can potentially be any loci available in the signing space. This strategy of coordination is notated here as COORDSHIFT $^{5}$ and is shown in Figure 2. Like COORD-L, COORD-SHIFT can be used in contexts that favor both disjunctive (9) and conjunctive (10) interpretations. For ease of comparing this to other forms of disjunction I have transcribed it in the way that manual signs are transcribed (as a separate word in small capital letters), when in reality it is just a change in position from one side of the body to the other; the placement of the notation 'COORD-SHIFT' marks the timing of this change in location. Subscripts on a bracketed constituent (e.g. in (9), POSS $a$ PARENTS WILL BUY POSS $a$ CAR) indicate that the entire constituent is signed at that locus (e.g. locus b).

(9) $\left[\text { POSS }_{a} \text { PARENTS WILL BUY POSS }{ }_{a} \text { CAR }_{b} \text { COORD-SHIFT [IX } a \text { WILL TRAVEL }\right]_{c}$ DON'T-KNOW WHICH.

'Her parents will buy her car or she will travel, I'm not sure which.'

5 "Shift" describes the shift in locations, and is separate from role shift, a common phenomenon in sign languages used for taking others' perspective in narratives and reported discourse. 

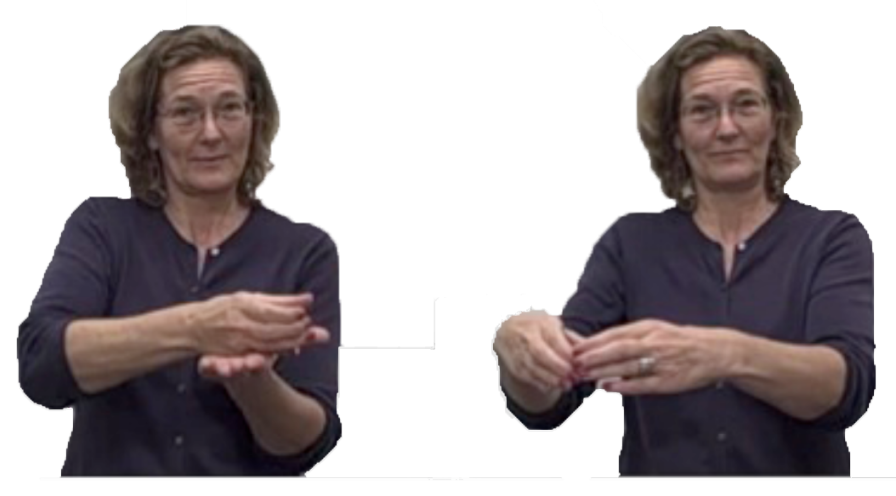

Figure 2 COORD-SHIFT: CUP COORD-SHIFT BOWL

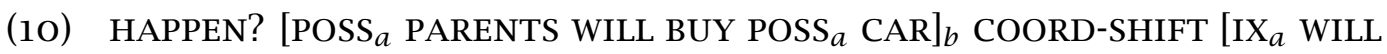
TRAVEL $]_{c}$.

'What will happen? Her parents will buy her car, and (then) she will travel.'

COORD-SHIFT can be used for alternative statements as well as both inclusive and exclusive readings in statements (11) although signers report that ideally its use in alternative questions would also co-occur with further clarifying linguistic information, such as a sentence-final wh-word WHICH.

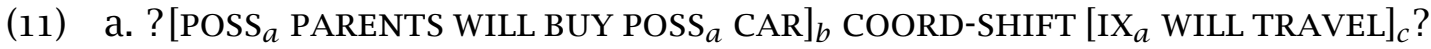
'Will her parents buy her car, or will she travel?'

b. $\left[\text { POSS }_{a} \text { PARENTS WILL BUY POSS } a \text { CAR] }\right]_{b}$ COORD-SHIFT [IX ${ }_{a}$ WILL TRAVEL $]_{c}$, WHICH?

'Will her parents buy her car, or will she travel?'

C. $\left[\text { POSS }_{a} \text { PARENTS WILL BUY POSS } a \text { CAR] }\right]_{b}$ COORD-SHIFT [IX $a$ WILL TRAVEL $]_{c}$, (DON'T-KNOW WHICH)

'Her parents will buy her car or she will travel, I'm not sure which.'

d. POOSS $_{a}$ PARENTS WILL BUY POSS $a$ CAR $_{b}$ COORD-SHIFT [IX $a$ WILL TRAVEL $]_{c}$, (MAYBE BOTH)

'Her parents will buy her car or she will travel, maybe both.'

Predicates (12) and noun phrases (13) can also be coordinated with COORDSHIFT, although again the alternative questions are judged to be improved 
'And' or 'or'

\begin{tabular}{llll}
\hline & $\begin{array}{l}\text { Alternative } \\
\text { Questions }\end{array}$ & $\begin{array}{l}\text { Exclusive } \\
\text { Statements }\end{array}$ & $\begin{array}{l}\text { Inclusive } \\
\text { Statements }\end{array}$ \\
\hline COORD-shift & $\begin{array}{l}\text { YES (preferred } \\
\text { together with }\end{array}$ & YES \\
& WHICH) & & \\
COORD-L & YES (for some, YES (for some, YES (for some, \\
& improved with improved with improved with \\
English or & 3ES coordinates) & 3+ coordinates) & 3+ coordinates) \\
& YES & YES
\end{tabular}

Figure 3 The use of general use coordination in ASL and English or in typical disjunction environments

with a sentence-final WHICH.

(12) a. MARY $[\mathrm{SWIM}]_{a}$ COORD-SHIFT $[\mathrm{RUN}]_{b}$, WHICH?

'Does Mary swim or run?'

b. MARY $[\text { SWIM }]_{a}$ COORD-SHIFT $[\mathrm{RUN}]_{b},(\mathrm{DON}$ 'T-KNOW WHICH).

'Mary swims or runs, I'm not sure which.'

c. MARY $[\mathrm{SWIM}]_{a}$ COORD-SHIFT $[\mathrm{RUN}]_{b}$, (MAYBE BOTH).

'Mary swims or runs, and maybe both.'

(13) a. MARY HAVE $[\text { COFFEE }]_{a}$ COORD-SHIFT [TEA $]_{b}$, WHICH?

'Did Mary have coffee or tea?'

b. MARY HAVE [COFFEE $]_{a}$ COORD-SHIFT [TEA $]_{b}$, (DON'T-KNOW WHICH).

'Mary had coffee or tea, I'm not sure which.'

c. MARY HAVE [COFFEE $]_{a}$ COORD-SHIFT [TEA $]_{b}$, (MAYBE BOTH).

'Mary had coffee or tea, and maybe both.'

In sum, we see that COORD-SHIFT, like COORD-L, has a wide syntactic distribution and one that is familiar to English speakers in mirroring the environments of English coordinators like or and and (Figure 3).

\subsection{3 "Iconicity" of COORD}

Before moving on to other coordinators, one note about the "iconic" aspects of these two forms of general use coordination in ASL: while both forms share 
physical similarities with the gestures that an English speaker might use when discussing lists of items (listing items on the hand or gesturing to points in space), ASL coordinators crucially differ from English co-speech gestures in that these movements can act as part of the grammar to coordinate items on their own (without other forms of coordination). It's certainly possible that either may have originated from non-linguistic gestures of listing items in the space in front of the body (for COORD-SHIFT) or on the fingers of the hand (for COORD-L), as the grammaticalization of gestures in sign languages is well documented (Janzen 1999, Janzen \& B Shaffer 2002; Wilcox \& Barb Shaffer 2006; Wilcox 2007, Pfau \& Steinbach 2011). In spoken language, these gestures seem to be able to be used with both conjunction and disjunction, and therefore it's perhaps not surprising that they may have evolved into general use coordinators in ASL, as opposed to strictly conjunction or disjunction. Moreover, even in ASL it is possible to add a different form of disjunction (such as O-R, discussed below) in addition to either of the general use coordinators seen here, to clarify that the coordination should be interpreted as disjunction. However, despite some of the physical properties that they share with gestures, these coordinators are unlike speakers' gestures in that they can be used as stand-alone linguistic elements to express coordination, as shown many times in this section.

\subsection{Other forms of disjunction and conjunction}

Although the availability of both 'and' and 'or' readings with general use coordinators COORD-L and COORD-SHIFT is striking from the point of view of English, it is important to note here that ASL does not lack lexical items that are uniquely interpreted as disjunction or conjunction. In fact, ASL has two signs that are always interpreted as disjunction when used to coordinate items.

The first of these unambiguous disjunctive coordinators, labeled "O-R", is a borrowing from English and is expressed using the ASL fingerspelling system: it consists of spelling first the letter "o" and then the letter " $r$ " using the manual alphabet. O-R has the same distribution and interpretation as English or: it appears in exclusive and inclusive statements as well as alternative questions, and coordinates clauses, VPs, and NPs. During the course of consulting with native signers about disjunction, a number of signers remarked on the fact that either general use coordinator can be paired with O-R to force a disjunctive reading. When combined with COORD-L, 
'And' or 'or'

$\mathrm{O}-\mathrm{R}$ is signed between coordinates, and when combined with COORD-SHIFT, $\mathrm{O}-\mathrm{R}$ is also signed between coordinates during the shift in location.

The second unambiguously disjunctive coordinator in ASL I'll label "oRWHICH", because it is homophonous with the wh-word that means WHICH in wh-questions such as (14).

\section{(14) MARY DRINK WHICH? \\ 'Which one did Mary drink?'}

Like the fingerspelled O-R, OR-WHICH can be used in both inclusive and exclusive interpretations of disjunction in statements, and can coordinate clauses, NPs, and VPs. Some (but not all) signers report it as awkward when interpreted as disjunction in alternative questions, possibly because there is an interfering meaning as the wh-word wHICH. ${ }^{6}$ On the other hand, this cannot be the entire explanation, because wh-questions have distinctive non-manual marking in ASL (eyebrow furrowing), and so nonmanuals alone should be sufficient to disambiguate these two uses. Another explanation for signers' preference against that sign is simply that it is going out of fashion: OR-WHICH is anecdotally reported to be historically older and used less frequently among young and middle-aged signers than among older generations, consistent with reports from Fischer 1996 and Shaw \& Delaport 2010 that the same sign occurs in the historically older language Langue des Signes Française (LSF/French Sign Language) with the meaning 'this one or that one'.?

Finally, there is also an overt conjunction, AND, in ASL. This sign is much less common in ASL than and in English, but it does frequently appear in ASL translations of English phrases (for example, book or movie titles like "Jack and the beanstalk") and is occasionally used for emphasis.

\section{Semantics of general use coordinators in ASL}

As examples in Section 1 make clear, the interpretations of COORD-L and COORD-SHIFT require us to account for two different interpretations of the same phonological forms. In this section, I first provide arguments against

6 A reviewer notes the interesting fact that for some English speakers, either ... or also cannot be used for alternative questions: Did he study either English or German?' only has the polar "yes/no" question reading.

7 Thanks to Peggy Lott for noticing this similarity. 
the hypothesis that general use coordinators in ASL are ambiguous in any sense of having separate lexical entries for the conjunctive and disjunctive interpretations. In other words, it does not seem to be the case that COORD-L and COORD-SHIFT each happen to be the same phonological realization of two separate lexical items. Rather, I argue that each COORD is a single lexical item (Section 3.1). I then provide a semantic analysis of the two general use coordinators COORD-SHIFT and COORD-L, suggesting that each COORD has a set-union semantics. The created set combines compositionally with the rest of the clause using a Hamblin 1973 style semantics. The final conjunctive or disjunctive interpretation arises via coordination-external universal or existential operators, respectively, on the set of clausal alternatives. In turn, these operators are licensed by various factors such as the semantic environment, context of utterance, nonmanual marking, and/or focus particles (Section 3.2).

\subsection{Arguments against lexical ambiguity}

First, let us review why each coORD is not simply a case of ambiguity. In a classic ambiguity, a single phonological form should correspond to two different (although potentially historically related) semantic representations (e.g. computer mouse and animal mouse). Such an approach is lacking in explanatory power in general, and ideally is to be avoided. There are, however two reasons beyond simple aversion to ambiguity that argue against this approach with general use coordination in ASL. First, there are two separate general use coordinators in ASL: COORD-L and COORD-SHIFT. If the terms are truly ambiguous, it would be doubly unlikely for the same ambiguity to have developed in two separate forms in ASL. Second, of the four native signers of ASL who contributed judgments to this paper, none had the intuition that COORD-SHIFT (also: COORD-L) when used as conjunction is meant to be a different word than COORD-SHIFT (also: COORD-L) when used as disjunction. Instead, each judged them to be the same word, although the interpretation depended on the context, for the simple reason that it is always possible to disambiguate the meaning with further lexical items. Both parsimony and native user's intuitions would then seem to argue against the simple ambiguity approach. Unfortunately, traditional tests against lexical ambiguity (e.g. conjunction reduction, ellipsis) can be overridden by intonation, and this (via nonmanual marking, below) is one common way to disambiguate the two readings of coORDs. However, section 4 presents a pragmatic study of the 
'And' or 'or'

interpretations of COORD-SHIFT which I take as one further another argument against an account in which the conjunctive and disjunctive interpretations are separate lexical items.

A second possibility, besides the lexical ambiguity account, is that the conjunctive and disjunctive interpretations of coORDs are two different lexical items differentiated not by manual signs but by nonmanual marking. As mentioned above, nonmanual marking includes movements of the face, head, and torso, which is notated on a separate tier; this is in contrast to the manual movements of the hands, notated using small capital letters. For both COORD-SHIFT and COORD-L, nonmanual marking can distinguish a disjunctive reading from a conjunctive reading: the same string can be interpreted disjunctively, with a squint and bit lip nonmanual marking (15)(16), which I'll notate as ' $s q$ ', or conjunctively, with a more neutral eyebrow nonmanual marking and the addition of a head nod (notated ' $h n^{\prime}$ ') (17)-(18).

(15) $\mathrm{IX}_{a}$ DRINK $\frac{s q}{\mathrm{TEA}_{b}}$ COORD-SHIFT $\frac{s q}{\operatorname{COFFEE}_{c}}$.

'She drank tea or coffee.'

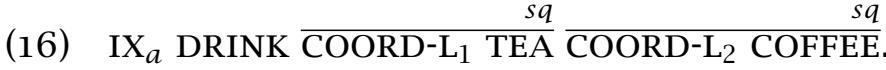

'She drank tea or coffee.'

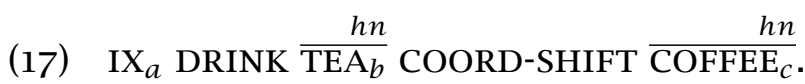

'She drank tea or coffee.'

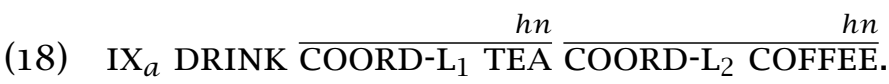

'She drank tea or coffee.'

Nonmanual marking can be thought of as analogous to intonation in spoken languages: it is produced concurrently with words/signs, and it serves many of the same functions as intonation, marking both affective emotion and grammatical distinctions such as topicalization, wh-questions, and polar questions. Like intonation, it is also perceptually salient to native signers. The distinction between (15) and (17) was in fact perceived by signers in an informal pilot study by the author. When viewing twelve sentences such as those above with disjunctive or conjunctive nonmanual marking, all three native signers correctly chose which of two pictures matched the sentence 
(one picture in which both disjuncts were true, or one in which only one was true). ${ }^{8}$

This pattern in (15)-(18) may suggest that nonmanual marking creates separate lexical items, for example COORD-SHIFT $+s q$ and COORD-SHIFTt $+h n$. However, there are reasons to believe that this is not the case. First, a lexical distinction via nonmanual marking would be rare within ASL. There are only a few lexical items in ASL for which nonmanual marking has been suggested to make a lexical distinction. One such example is LATE and NOT-YET, but these are extremely rare and even in the case of LATE and NOTYET involve a change in movement, as well as nonmanual marking. ${ }^{9}$ Much more common is for nonmanual marking to mark information structure or speech act distinctions, such as the difference between a polar question (with brow raising nonmanual marking) and a declarative statement (no special nonmanuals). This is similar to spoken language intonation and not to, for example, lexical tone distinctions.

A second reason to discount the nonmanual-lexical-ambiguity theory is that while nonmanual marking can distinguish the conjunctive and disjunctive meanings, it does not seem to be required for either interpretation. Consider (19)-(22) where there is no difference in nonmanual marking; instead, the interpretation is made clear via discourse particles вотн and EITHER, or via morphologically distinctive anaphora (an arc movement indexical point ("IX") marks plural, while an alternating movement indexical point is analogous to EITHER).

(19) $\mathrm{IX}_{a}$ DRINK TEA $b$ COORD-SHIFT COFFEE $c$, BOTH /IX 'She drank tea and coffee, both/them.'

(20) IX $_{a}$ DRINK TEA COORD-SHIFT COFFEE $_{c}$, EITHER/IX $_{b c \text { (alternating). }}$ 'She drank tea or coffee, either/either-one.'

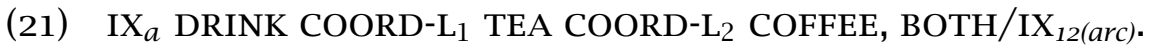
'She drank tea and coffee, both/them.'

8 Stimuli used in this small pilot study were the same as those used in the study presented below in Section 4, where more details are provided concerning the sentences and the pictures.

9 Thanks to Diane Lillo-Martin for this point. 
'And' or 'or'

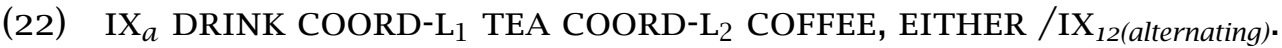
'She drank tea or coffee, either/either-one.'

One area where we naturally see discourse particles like BOTH and EITHER functioning to disambiguate the conjunctive from disjunctive reading is when the coordination appears in a context that already provides nonmanual marking. For example, relativized noun phrases typically have brow raising ('br') nonmanual marking (23)-(25). ${ }^{10}$ Without an additional discourse particle, judgments of the meaning of a general use coordinator (here, COORD-SHIFT) inside a relative clause vary, with a conjunctive interpretation felt by signers to be somewhat more salient, although the disjunctive interpretation was also available (23). All signers remarked that the most natural way to sign the sentence was to add a discourse particle like вотн or an indexical arc for a conjunctive interpretation (24), or EITHER or an alternating indexical point for a disjunctive interpretation (25).

(23) ${\text { SOME GIRL DRINK COFFEE } a \text { COORD-SHIFT TEA } \text { TOW }_{b}}_{\text {SICK. }}$ 'Some of the girls who drank coffee and (/?or) tea are now sick.'

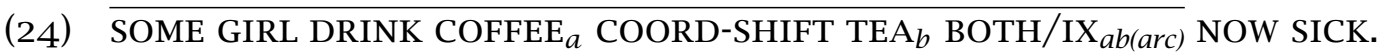
'Some of the girls who drank both coffee and tea are now sick.'

(25) SOME GIRL DRINK COFFEE COORD-SHIFT TEA EITHER/IX NOW SICK.

'Some of the girls who drank either coffee or tea are now sick.'

In sum, we see nonmanual marking is just one of many factors that determine whether cOORDs are interpreted conjunctively or disjunctively: a complete semantic/pragmatic analysis would not incorporate the nonmanual marking into the semantics of COORD-SHIFT or COORD-L, but would leave room for other pieces of the language like discourse particles to serve this function.

10 The brow raising in (23)-(25) may also be marking topicalization, which works equally well for making this point. 


\subsection{Compositional analysis}

Both the simple lexical ambiguity account and the nonmanual marking account would have taken a COORD with its meaning as disjunction to be a separate lexical item from the same cOORD with its meaning as conjunction. This does not seem to account for signers' intuitions, so we conclude in Section 3.1 that it is best to give a single semantics for each COORD. I propose that COORD-SHIFT (26) and COORD-L (27) each perform the function of set union.

\section{(26) $\llbracket A$ COORD-SHIFT $B \rrbracket=\llbracket A \rrbracket \cup \llbracket B \rrbracket$}

(27) $\llbracket A$ COORD-L $B \rrbracket=\llbracket A \rrbracket \cup \llbracket B \rrbracket$

Under these definitions, COORD-SHIFT and COORD-L take sets as arguments. However, we have seen that both cooRDs coordinate a wide range of coordinates. To coordinate all types of arguments, and to allow the conjunctive or disjunctive force to be separate from the set union, we can use rules proposed by Hamblin 1973. Let typical lexical items be simply mapped to the singleton set of their normal denotation, e.g. $\llbracket$ coffee $\rrbracket=\{c\} .{ }^{11}$ In certain cases specified in the theory, a lexical item may be mapped to a set of more than one individual or "alternative" (e.g. $\{c, t\}$ ). Wh-words are one example: in a situation where coffee and tea are the only inanimate entities under consideration and we are computing the meaning of the question What does Mary drink? (28), the contribution of the wh-word what is the set of individuals $\{c, t\}(\mathrm{i})$.

(28) What does Mary drink? (/Mary drinks what?)

i. $\llbracket$ what $\rrbracket=\{c, t\}$

ii. $\llbracket \operatorname{drinks} \rrbracket=\left\{\lambda y \lambda x \lambda w \cdot \operatorname{drink}_{w}(x)(y)\right\}$

iii. 【drinks what $\rrbracket=\left\{\lambda x \lambda w \cdot \operatorname{drink}_{w}(x)(\{c, t\})\right\}$ $=\left\{\lambda x \lambda w \cdot \operatorname{drink}_{w}(x)(c), \lambda x \lambda w \cdot \operatorname{drink}_{w}(x)(t)\right\}$

iv. $\llbracket \operatorname{mary} \rrbracket=\{m\}$

v. «mary drinks what $\rrbracket$

$$
=\left\{\lambda w \cdot \operatorname{drink}_{w}(m)(c), \lambda w \cdot \operatorname{drink}_{w}(m)(t)\right\}
$$

11 For simplicity, I am taking coffee and tea to behave like proper names in being rigid designators and having constant denotations across worlds. 
'And' or 'or'

This set $\{c, t\}$ is taken as the argument of the transitive predicate drinks, where it combines using pointwise functional application, creating a set consisting of combinations of each element in the argument set (here, $\{c, t\}$ ) and each element in the applied function (here, $\left\{\lambda y \lambda x \lambda w \cdot \operatorname{drink}_{w}(x)(y)\right\}$ ) (ii)-(iii). Formally, this is captured in Hamblin's rule of composition (29), as presented by Alonso-Ovalle 2009.

(29) Hamblin's Rule of Composition

If $\llbracket \alpha \rrbracket \subset D_{<\sigma, \tau>}$ and $\llbracket \beta \rrbracket \subseteq D_{\sigma}$, then $\llbracket \alpha(\beta) \rrbracket=\left\{c \in D_{\tau} \mid \exists a \in \llbracket \alpha \rrbracket, \exists b \in \llbracket \beta \rrbracket(c=a(b))\right\}$

As the derivation continues, the set of alternatives keeps "expanding" (i.e. continues combining with other arguments as sets of alternatives) until it meets an operator that selects for a set of alternatives or reaches the end of the derivation. In (28), the singleton set containing Mary ( $\{m\})$ (iv) enters into the composition, saturating the final argument position to result in a set of two propositions, one the set of worlds where Mary drinks coffee, and one the set of worlds where Mary drinks tea (v).

Hamblin's semantics for questions, then, results in a set of propositions that are possible answers to the question. Based on the behavior of questions under embedding predicates, Karttunen 1977 suggested that the result should actually be the set of true answers to the question. Since this overall "alternative" approach to question semantics was proposed there have been extensive discussions about the semantics of questions and predicates that embed them (e.g. know, ask, etc.), but undoubtedly alternative semantics has been broadly influential and remains at least one of the leading accounts for question semantics. Subsequently, alternative semantics has been used in the analysis of other phenomena, such as focus and focus-sensitive particles (Rooth 1992) and indefinites (Kratzer \& Shimoyama 2002).

Of course, we are concerned here with how to potentially use these rules of alternative semantics for coordination by set union. In fact, such an analysis has already been proposed for disjunction by Alonso-Ovalle 2006, and shares some properties of disjunction as modeled by Groenendijk 2009, Groenendijk \& Roelofsen 2009 in preserving information about the individual coordinates (specifically, the disjuncts) throughout the semantic computation. Although multiple factors motivate these alternative-based approaches to disjunction, the one that concerns us here and is important for the analysis of general use coordination in ASL is that the (disjunctive or conjunctive) force of the coordinator can be external to the coordinated 
clause. In other words, the semantic contribution of the coordinator is simply to collect alternatives. Whether the semantic composition requires just one of these alternatives to be true (as in disjunction) or all to be true (as in conjunction) is determined by a separate entity in the semantics (a clause-external operator) that acts upon the set of alternatives. In the case of disjunction, an operator with existential quantificational force acts upon the set of alternatives. In the case of conjunction, the operator has universal quantificational force. According to Alonso-Ovalle, his data suggest strong reasons to take such an approach to disjunction, but "it remains to be seen whether there are reasons to believe that the universal force of and is also external" (p. 13). I propose that general use coordination in ASL provides an ideal case for proposing a single semantics of conjunction and disjunction, with the difference in interpretations provided by an operator that is external to the coordinated constituent.

To be concrete about how an external operator can work for ASL, consider (30). This sentence uses a general use coordinator, COORD-SHIFT. In the absence of a clear differentiating context, nonmanual marking, or discourse particles, COORD-SHIFT can be interpreted disjunctively ('Mary drank tea or coffee') or conjunctively ('Mary drank tea and coffee'). We can now model these two possibilities. Using the semantics for COORD-SHIFT proposed in (26), we take the meaning of the conjunctive noun phrase COFFEE COORDSHIFT TEA to be the set containing two members, coffee and tea (i). When this set is taken as the complement of the verb DRINK, Hamblin's Rule of Composition leaves us with a set of two members: the set of entities that drink coffee, and the set of entities that drink tea (iii). Finally, we add MARY as the final argument, returning a set with two propositions: the set of worlds where Mary drinks coffee, and the set of worlds where Mary drinks tea (v).

(30) MARY DRINK COFFEE $a$ COORD-SHIFT TEA . $_{a}$

i. $\llbracket$ COFFEE $\rrbracket=\{c\}, \llbracket T E A \rrbracket=\{t\}$

$\llbracket \operatorname{COFFEE}_{a}$ COORD-SHIFT TEA $_{b} \rrbracket=\{c, t\}$

ii. $\llbracket$ DRINK $\rrbracket=\left\{\lambda y \lambda x \lambda w \cdot \operatorname{drink}_{w}(x)(y)\right\}$

iii. 【DRINK COFFEE $a$ COORD-SHIFT TEA $b \rrbracket$

$=\left\{\lambda x \lambda w \cdot \operatorname{drink}_{w}(x)(\{c, t\})\right\}$

$=\left\{\lambda x \lambda w \cdot \operatorname{drink}_{w}(x)(c), \lambda x \lambda w \cdot \operatorname{drink}_{w}(x)(t)\right\}$

iv. $\llbracket M A R Y \rrbracket=\{m\}$ 
'And' or 'or'

$$
\begin{aligned}
& \text { V. 【MARY DRINK COFFEE } \text { COORD-SHIFT TEA }_{b} \rrbracket \\
& =\left\{\lambda w \cdot \operatorname{drink}_{w}(m)(c), \lambda w \cdot \operatorname{drink}_{w}(m)(t)\right\}
\end{aligned}
$$

Such an account successfully avoids committing to a disjunctive or conjunctive interpretation of COORD-SHIFT as part of its semantic contribution. However, as it stands, the analysis above is incomplete. The interpretation of the sentence in (30) is a set of propositions (v), which is the same semantics Hamblin suggests for questions, but (30) is clearly not a question! ${ }^{12}$ We will need something additional in our semantics to take the set of propositions provided in (30) and return a single proposition. I propose that the grammar makes available a set of two quantifiers that apply to the set of propositions and return just one proposition: one quantifier has existential force and is defined as in (31) (Alonso-Ovalle 2006), the other has universal force and is defined as in (32).

(31) $\exists P=\lambda w \cdot \exists p[p \in P \wedge p(w)]$

(32) $\forall P=\lambda w \cdot \forall p[p \in P \rightarrow p(w)]$

The existential quantifier (31) takes a set of propositions $P$, and returns the set of worlds where at least one proposition in the set $P$ contains that world. The resulting proposition is equivalent to the traditional Boolean disjunction after acting upon the set of alternatives provided by COORD. Consider a situation in which the context has licensed an existential quantifier, resulting in COORD-SHIFT having a disjunctive interpretation (33). The resulting proposition is the set of worlds where Mary drank coffee or Mary drank tea (vii).

(33) MARY DRINK COFFEE $a$ COORD-SHIFT TEA . 'Mary drank coffee or tea.'

vi. $\exists P=\lambda w \cdot \exists p[p \in P \wedge p(w)]$

vii. $\exists\left[\right.$ MARY COFFEE $_{a}$ COORD-SHIFT TEA $\left._{b}\right]$

$$
\left.=\lambda w \cdot \exists p\left[p \in\left\{\lambda w \cdot \operatorname{drink}_{w}(m)(c), \lambda w \cdot \operatorname{drink}_{w}(m)(t)\right\} \wedge p(w)\right]\right]
$$

12 On the other hand, the close relationship between disjunction and questions is explored in depth within the framework of Inquisitive Semantics. See Groenendijk 2009 and Groenendijk \& Roelofsen 2009. 
Kathryn Davidson

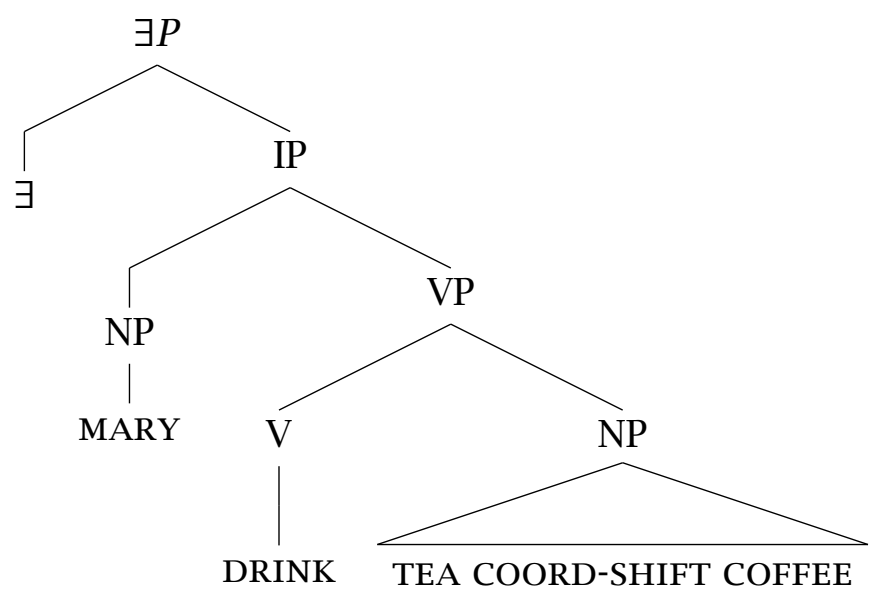

The tree illustrates the hierarchy of the semantic composition. In the case where the universal quantifier has been licensed, the semantics would be exactly the same with the universal quantifier in (32) replacing the existential. The result is the set of worlds in which every proposition is true, i.e. the traditional Boolean conjunction.

Under this analysis, the universal and existential quantifiers are always both available in the grammar, while the choice is conditioned by the (linguistic or nonlinguistic) context. Although the full range of factors that condition these readings could be a much larger research project on its own, we have already seen some important licensors. Licensors for universal quantification include head nod nonmanual marking, the addition of вотн, or the addition of an indexical arc (typically used for plural marking of pronouns) over the loci of the coordinates (34). Some licensors for existential quantification are a squint and bit lip nonmanual marking, a discourse particle like EITHER, or indexical pointing with an alternating movement between the loci of the coordinates (35).

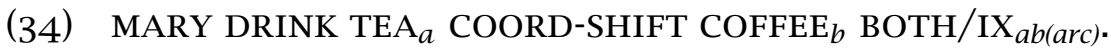
'Mary drinks tea and coffee, both/them both.'

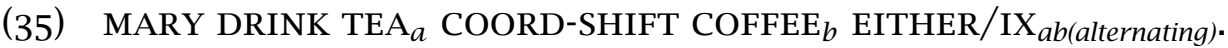
'Mary drinks tea or coffee, either one.'

In English, multiple coordinators can be used in the same syntactic argument position (36). In ASL, this is also possible with two occurrences of a COORD. In (37), COORD-SHIFT is used twice, once interpreted as conjunction and once as disjunction. The sentence is signed with locations $a$ and $b$ 
'And' or 'or'

"contained" in $c$ (e.g. both are signed on the signer's left side, locus $c$, while locus $d$ is on the right), so the hierarchical organization of the locations in sign spaces matches the hierarchical organization of the linguistic constituents. Conjunctive or disjunctive interpretations are distinguished in the usual ways, as seen in (37) in the nonmanual marking $h n$ for the conjunctive readings of the inner-most COORD-SHIFT, and the discourse particle clarifying the disjunctive interpretation of the outer-most COORD-SHIFT.

(36) Mary drank [coffee and tea] or [wine].

(37) MARY DRINK $\left[\frac{h n}{\operatorname{COFFEE}_{a}} \text { COORD-SHIFT } \frac{h n}{\operatorname{TEA}_{b}}\right]_{c}$ COORD-SHIFT WINE $_{d}$, EITHER/IX cd(alternating)

'Mary drank [coffee and tea] or [wine].'

However, in the semantics as it is currently proposed, two consecutive applications of set union will result in a single set with three elements (38). Because this set no longer has any hierarchical structure, separate conjunctive and disjunctive interpretations for subsets will not be available.

$\left[\frac{h n}{\operatorname{COFFEE}_{a}} \operatorname{COORD} \text { SHIFT } \frac{h n}{\operatorname{TEA}_{b}}\right]_{c}$ COORD-SHIFT WINE , EITHER/IX $_{c d(\text { alternating) }}$

i. $\llbracket \operatorname{COFFEE}_{a}$ COORD-SHIFT TEA $_{b} \rrbracket=\{c, t\}$ $\llbracket \mathrm{WINE}_{d} \rrbracket=\{w\}$

ii. $\llbracket\left[\operatorname{COFFEE}_{a} \text { COORD-SHIFT TEA }_{b}\right]_{c}$ COORD-SHIFT WINE $_{d} \rrbracket=\{c, t, w\}$

There are at least two kinds of adjustments to the proposal that can account for these examples. The first is to assume that conjunction as seen in the inner coordination in (37) is actually a different type of conjunction, used in creating plural sums (Link 1983, Hoeksema 1988). This is preliminarily supported by signers' preference for the example in (37) over one where disjunction is the inner coordinator and conjunction is the outer. If this preference turns out to be especially strong, then a plural semantics for the inner conjunction could account for this difference, and there would only be one true coordination (disjunction) in (37). If, on the other hand, further investigation suggests that we do need to permit true coordination for both the inner and outer coordinates, then a solution will require a semantics that preserves the hierarchical structure of multiple coordination, allowing each instance of coordination to be accessible to higher-up existential and 
universal operators. Such a hierarchical syntactic/semantic structure is already required for "nested" coordination like She drank coffee and tea and wine (Winter 2007), and so a similar solution should account for both phenomena.

We have also not yet addressed the possibility that one of the two interpretations (say, conjunction, or disjunction) may be the basic meaning, and the other interpretation is derived from the first. In fact, an analysis along these lines has been proposed for modals in St'at'imcets (Rullmann, Matthewson \& Davis 2005, Matthewson 2010) and in Nez Perce (Deal 2011). On the surface, the behavior of modals in these languages looks similar to general use coordination in ASL. For example, the Nez Perce modal particle o'qa has two interpretations: one reading involves existential quantification force (specifically, existential quantification over worlds, like English may, can) (39a), while the other involves universal quantification over worlds (compare with English must, should) (39b) (Deal 2011, example (2)).

(39) Context: a friend is preparing for a camping trip. I am taking this person around my camping supplies and suggesting appropriate things. I hand them two blankets and say: 'inéhne-no'qa 'ee kii lepít cíickan. take-MODAL you DEM two blanket

a. 'You can take these two blankets.'

b. 'You should take these two blankets.'

Deal argues that the basic quantification force of $o$ 'qa is existential, but that the universal reading is available because there is no other lexical item in the language with that meaning. Because the universal reading is strictly stronger than the existential reading (just as conjunction entails disjunction), use of the weaker term is strictly consistent with both interpretations, and is pragmatically consistent in Nez Perce because there is no stronger modal. She supports this with data showing that only the weaker reading is available in contexts where scales are reversed, such as the antecedent of conditionals ((40), (58) in Deal 2011) or negation. 
'And' or 'or'

(40) c'alawí saykiptaw'atóo-nm háamti'c páa-x-no'qa, simíinikem-x if doctor-ERG quickly 3/3-see-MODAL, Lewiston-to

hi-kiy-ó'qa

3SUBJ-go-MODAL

a. 'If the doctor can see him in a hurry, then he should head over to Lewiston'

b.\#'If the doctor needs to see him in a hurry, then he should head over to Lewiston'

It is in these environments that we see that the similarity does not extend to ASL. When we look at scale reversing (typically, downward entailing) contexts, we find that general use coordination shows a very different pattern. For both general use coordinators in ASL, conjunction (the stronger, 'universal quantification' term) is an available reading in a downward entailing context. Disjunction, which is entailed by conjunction and hence the 'weaker' reading, was judged to be unavailable in the antecedent of a conditional for COORDSHIFT (41). For COORD-L (42) consultant judgments varied, but all felt that the conjunctive reading was available, and for some consultants both readings were available under the antecedent of a conditional. Under negation, only the conjunctive reading appears to be available (43)-(44).

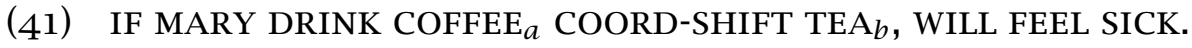

a. \#'Mary will feel sick if she drank either coffee or tea.'

b. 'Mary will feel sick if she drank both coffee and tea.'

(42) IF MARY DRINK COORD-L $\mathrm{L}_{1}$ COFFEE COORD-L 2 TEA, WILL FEEL SICK.

a.\%'Mary will feel sick if she drank either coffee or tea'.

b. 'Mary will feel sick if she drank both coffee and tea.'

(43) IX IX GIRL NOT DRINK COFFEE $_{b}$ COORD-SHIFT TEA $_{c}$.

a. \#'That girl didn't drink coffee or didn't drink tea'

b. 'That girl didn't drink coffee and didn't drink tea.' 
(44) IX $_{a}$ GIRL NOT DRINK COORD-L $\mathrm{L}_{1}$ COFFEE COORD-L $\mathrm{T}_{2} \mathrm{TEA}_{c}$.

a. \#'That girl didn't drank coffee or didn't drink tea'

b. 'That girl didn't drink coffee and didn't drink tea.'

This is the opposite pattern from the modals in Nez Perce, where the modal with existential force was the only available reading in downward entailing environments.

What might account for the pattern in (41)-(42)? Like relative clauses, the antecedents of conditionals provide their own nonmanual marking, which could potentially interfere with nonmanual marking that could help distinguish the two readings of COORD-SHIFT or COORD-L. In fact, signers preferred some disambiguating discourse particles along with COORD-SHIFT (45)-(46) or COORD-L (47)-(48), and just as we saw with relative clauses in (23)-(25), both readings then become available.

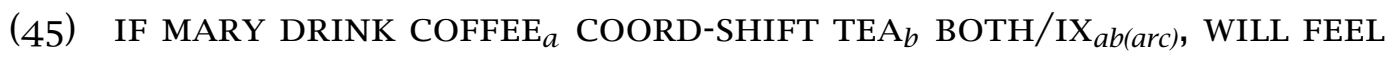
SICK.

'Mary will feel sick if she drank both coffee and tea.'

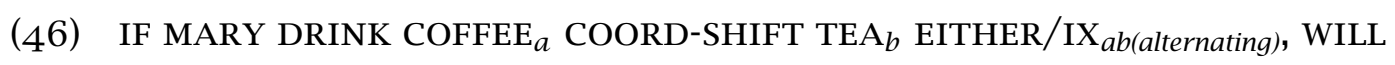
FEEL SICK.

'Mary will feel sick if she drank either coffee or tea.'

(47) IF MARY DRINK COORD-L 1 COFFEE COORD-L 2 TEA BOTH/IX ${ }_{12(a r c)}$, WILL FEEL SICK.

'Mary will feel sick if she drank both coffee and tea.'

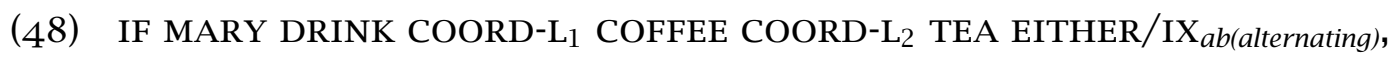
WILL FEEL SICK.

'Mary will feel sick if she drank either coffee or tea.'

Note also that we can confirm that these judgments concern nonmanual marking, and not the downward entailing context, because we found the same pattern even in relative clauses following SOME (23)-(25), which is an upward entailing environment.

We conclude that neither pattern seen for COORD-SHIFT or for COORD-L is consistent with a story in which the disjunctive meaning is the basic meaning. Furthermore, I see no way to posit conjunction as the basic meaning of the 
'And' or 'or'

general use coordinators and then derive the disjunctive reading, because disjunction is strictly weaker. If an interlocutor were to attempt to express disjunction and only had a conjunctive coordinator to use, they would in many cases be making false claims that no amount of pragmatic reasoning could rescue.

In sum, we have seen that general use coordinators in ASL share many of the same distributional properties as their English counterparts and and or. Despite the similarity, I argued that the best analysis of general use coordination would not be a lexical ambiguity between their 'or' and 'and' readings, but rather a single semantics of set union for each general use coordinator (COORD-SHIFT and COORD-L). The general use coordinator creates a set that can compose according to rules developed for question and focus semantics. The set of alternatives is quantified over by an existential or universal quantifier, which provides the disjunctive and conjunctive readings. Other languages, of course, also express conjunction and disjunction, and it is an open question whether they should also be analyzed with alternatives, or if that need only be the case in languages like ASL and possibly Maricopa and Japanese. While this paper makes no claims requiring this analysis to extend to other languages, there are independent reasons that alternatives have been suggested already for the analysis of disjunction and conjunction, and an ideal theory would provide a similar analysis across all languages, including ASL.

One major question remaining in this picture is how these readings come about. We have seen that nonmanual marking, focus particles like вOTH and EITHER, and even indexical points with different movements (IX ab(alternating) Vs. $\left.\mathrm{IX}_{a b(a r c)}\right)$ license the appropriate existential or universal operator. Untangling the contributions of each of these items requires further research. To illustrate one way of researching this question, the final section of this paper investigates the relationship of one of these factors, nonmanual marking, to the interpretation of COORD-SHIFT. In particular, it focuses on one pragmatic consequence of having the same phonological form used for conjunction and disjunction with disambiguation coming from nonmanual marking: the availability of scalar implicatures typically associated with the exclusive reading of disjunction. 


\section{Scalar implicatures associated with one general use coordinator}

This section presents a small experimental investigation of the role of one of the factors that licenses conjunctive and disjunctive interpretations of general use coordination in ASL: nonmanual marking. In particular, this section explores the question of how strongly the nonmanual marking is or is not a part of the coordinator for the pragmatic purpose of creating a set of alternatives (a "scale") for computing scalar implicatures. Recall that signers judge COORD-SHIFT with disjunctive nonmanual marking to have a different interpretation ('or') than general use coordination when appearing with conjunctive nonmanual marking. This distinction is clear enough for a same/difference judgment by native signers, but prompts the semantic/pragmatic question of whether such a nonmanual distinction is, in a sense, "strong" enough to create a lexical scale upon which scalar implicature would be calculated. The scale formed by English 〈and, or 〉 is one of the most well-studied of the prototypical "Horn scales", and so here we take the opportunity to investigate whether the same effects that are seen in English are also seen with COORD-SHIFT and disambiguating nonmanual marking. There are many examples in the literature testing scalar implicature calculation in languages other than English (Noveck 2001, Papafragou \& Musolino 2003, Slabakova 2010, among others) and all find similar behavioral results in their participants with prototypical scales like $\langle$ and, or $\rangle$. Results generally do not show cross-linguistic variation in scalar implicatures, unless there is something unique about the scale itself. In this case, we test whether the general use coordinator COORD-SHIFT can form a 'scale' based on disjunctive and conjunctive nonmanual marking.

This appears to be the first experiment testing a language that completely lacks a distinction in lexical form (i.e. manual sign, not the nonmanual marking) between potential scalar items. If calculation by deaf native signers on the coordination scale in ASL looks just like other conventional scales in ASL, and like the coordination scale in English, then we can conclude that manual/lexical contrast is not an important feature of a semantic scale, and that nonmanual marking plus the general use coordinator is sufficient to form

a scalar contrast. On the other hand, if there is decreased scalar implicature calculation on the coordination scale in ASL compared to other scales in ASL, or compared to the coordination scale in English, this would indicate that the combination of nonmanual marking plus a general use coordinator is not pragmatically equivalent to and or or in English. The experiment below tests 
'And' or 'or'

these predictions, and finds that there are fewer scalar implicatures based on coordination in ASL. I end with conclusions about the pragmatics of general use coordination in ASL, and the nature of semantic scales more generally.

\subsection{Methods}

Participants Participants were 22 adults from the greater San Diego area. Ten were adults who self-identify as Deaf and have been learning and using American Sign Language from birth because they had at least one deaf parent. All were deaf to the extent that they were unable to hear normal speech, and all used ASL in their home, at work, or both. These participants were recruited directly through email requests from a laboratory database of interested participants or indirectly through recommendations by friends. All received reimbursement in cash or gift cards. I will refer to these ten participants as "native signers of ASL". The twelve remaining participants were typically hearing undergraduate students at the University of California who were monolingual native speakers of English and have had no exposure to ASL. These participants received course credit for participating in the experiment. I will refer to these participants as "native speakers of English".

Procedure Each testing session lasted 30-35 minutes. The participant sat in front of a 13 inch laptop on a table, either at UCSD or, for some native signers of ASL, at various meeting places throughout San Diego county. Both the instructions and the task itself were presented on the laptop in video form, by a native signer of ASL (ASL version) or a native speaker of English (English version). Participants were instructed that for each trial of the experiment, a picture would appear on the screen, and that after looking at the picture, they should press a key and a video description will begin to play next to the picture. Participants were told to press the smile face (the "1" key covered with a smile face sticker, directly below the picture of a smiling face on screen) if they were "satisfied that the description matches the picture." If they were "not satisfied, and think that the description does not match the picture", they were instructed to press the frown face (the "o" key covered with a frown face sticker, directly below the picture of the frowning face on screen) (Figure 4). It was impossible in both the ASL version and in the English version to replay a video.

Participants saw three practice trials to acquaint them with the task: (1) a

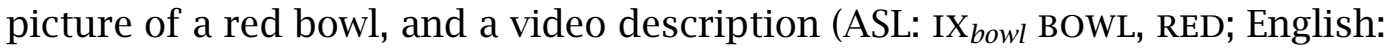




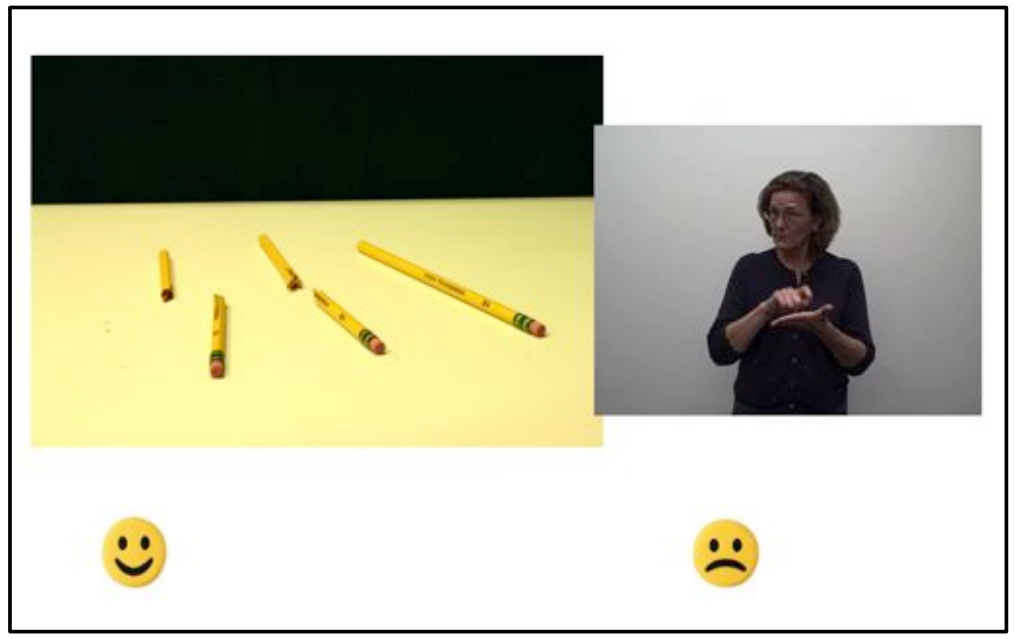

Figure 4 Screenshot during an ASL quantifier experimental trial. The picture is always on the left, and the signed description of the picture appears on the right.

"The bowl is red"); (2) a picture of a white shoe, and a video description (ASL: $\mathrm{IX}_{\text {shoe }}$ SHOE, BLACK; English: "The shoe is black"); (3) a picture of a wooden spoon, and a video description (ASL: $\mathrm{IX}_{\text {spoon }}$ SPOON, WOODEN; English: "The spoon is wooden"). Practice trials were followed by further instructions, and a confirmation that the task was understood. Finally, 48 experimental trials were presented. Of these, 24 were fillers used as experimental conditions for other studies, and 24 were experimental conditions in the current study. The current experiments' 24 trials consisted of 12 trials of each sentence type: (a) Quantifiers, which are a prototypical scale in ASL and in English and (b) Coordination, which has a lexical contrast in English but only a nonmanual contrast in ASL. Responses were recorded using Psyscope experimental software.

\subsection{Trial Types}

Quantifiers The quantifier scale was used as the baseline case for scalar implicature calculation in this experiment. As in coordination, ASL has multiple signs that can be translated into English as 'some' or 'all'. Figure 5 illustrates the version of the quantifiers SOME and ALL used in this study. These quantifiers can serve as a prototypical scale in ASL because they 
'And' or 'or'

contrast lexically in the same way in ASL as they do in English. Based on all previous research on these types of scales in other languages (Papafragou \& Musolino 2003) as well as in ASL (Davidson 2011), they were expected to pattern like their English counterparts.

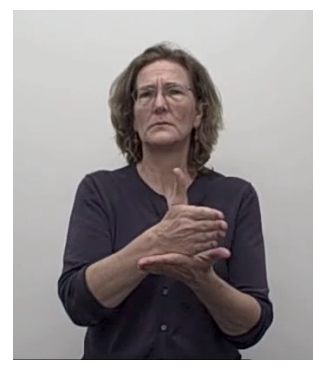

SOME

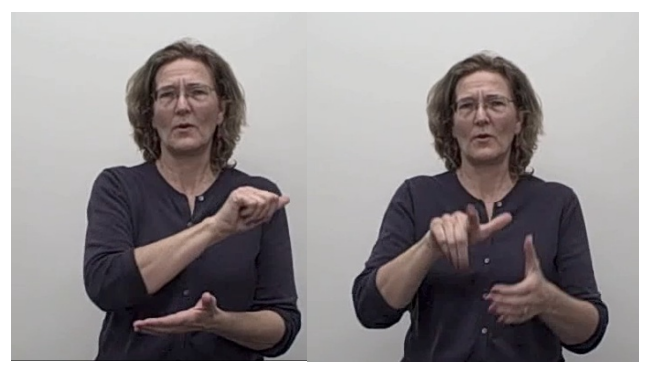

ALL

Figure 5 SOME and ALL used in the Quantifier sentence type.

In Quantifier trials, each picture consisted of a set of three objects of which either only some of the objects or all of them fulfilled a characterization about that object (e.g. red cans, lit candles, full glasses, etc.) A schema is shown in Figure 7. Under the Match condition, the characterization applied to all of the objects (e.g. three cans, all red), and the description was accurate (e.g. CANS, ALL RED 'All of the cans are red.'). Under the Mismatch condition, the characterization applied to only two of the objects (e.g. three cans, only two are red), and the description was not accurate (e.g. CANS, ALL RED 'All of the cans are red.'). Finally, under the Test condition, the characterization applied to all of the objects (e.g. three cans, all red), and the description was not maximally informative (e.g. CANS, SOME RED 'Some of the cans are red.'). In this way, the weak scalar term some was only evaluated by participants in the Test condition, so that they were never directly comparing this condition to use of the term when it was maximally informative. Trials for all sentence types were counterbalanced so that each sentence frame (e.g. red cans) appeared in only one trial type (Match, Test, Mismatch) for each participant, and each third of the participants saw the sentence frame in a different trial type.

Coordination As discussed throughout this paper, coordination in ASL is a complex topic. There are multiple ways to test the pragmatic interpretation 
of conjunction or disjunction in ASL, but the issue under investigation in this study is whether the general use coordinator COORD-SHIFT, which could potentially form the scale 〈COORD-SHIFT(AND), COORD-SHIFT(OR)〉 based on disambiguating nonmanual marking, has the same pragmatic interpretation (i.e. a scalar implicature interpretation) as the lexically contrastive $\langle$ and, or $\rangle$ scale in English. In this experiment each trial was always a declarative sentence: the test was whether it was interpreted as exclusive or inclusive disjunction. When interpreted as disjunction, there was squinting and bit lip nonmanual marking on the disjuncts (see Figure 6), which as a whole was labeled "COORDSHIFT(OR)". The same coordinator with head nodding nonmanual marking conveying a conjunctive interpretation was labeled "COORD-SHIFT(AND)".

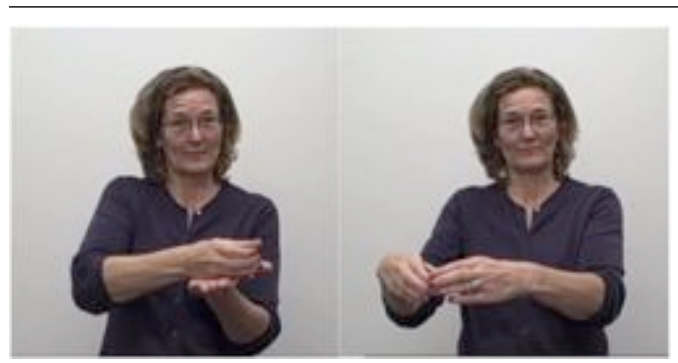

CUP $_{\mathrm{a}}$ COORD-SHIFT(AND) BOWL

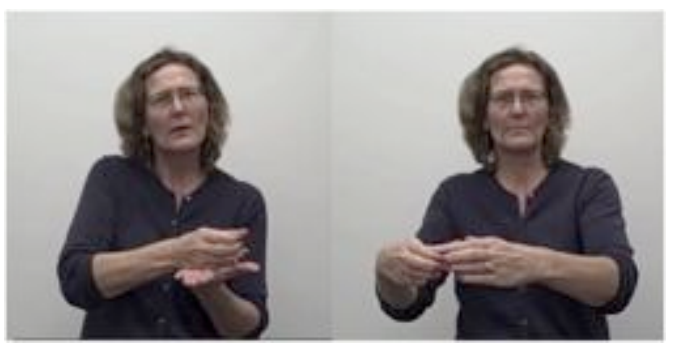

CUP $_{\mathrm{a}}$ COORD-SHIFT(OR) BOWL

Figure 6 COORD-SHIFT(AND) and COORD-SHIFT(OR) used in the Coordination sentence type.

In each of the Coordination trials, the picture consisted of two different objects (e.g. a mug and a bowl), and then either one or two of the same type of object (e.g. spoons) in relation to the first objects. The schema can be seen in Figure 7. In the Match condition in these trials, each of the two different objects were related to one of the similar objects, and the description was accurate (e.g. HAVE CUP SPOON(IN-CUP) COORD-SHIFT(AND) BOWL SPOON(IN-CUP). 'A spoon is in the mug and a spoon is in the bowl.'). Under the Mismatch condition, only one of the two different objects were related to one of the similar objects, but the description said that they both were equally related (e.g. HAVE CUP SPOON(IN-CUP) COORD-SHIFT(AND) BOWL SPOON(IN-CUP). 'A spoon is in the mug and a spoon is in the bowl.'). Finally, under the Test condition, each of the two different objects were related to one of the similar objects, but the description was not maximally informative due to the disjunctive nonmanual marking on the general use coordinator (e.g. 
'And' or 'or'

HAVE CUP SPOON(IN-CUP) COORD-SHIFT(OR) BOWL SPOON(IN-CUP) 'A spoon is in the mug or a spoon is in the bowl').

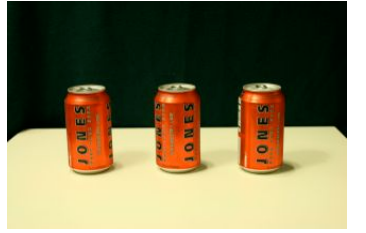

"Some of the cans are red."

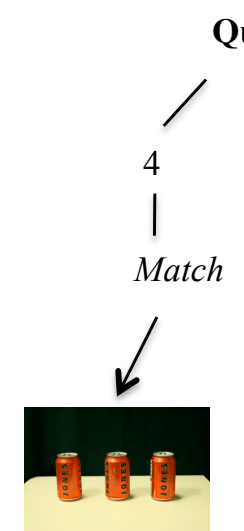

"All of the cans are red."

Quantifiers

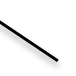

4

1

Test Mismatch (above)

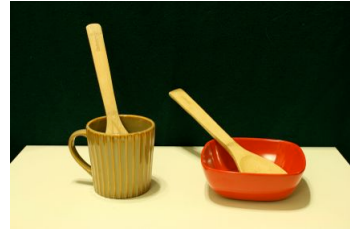

"A spoon is in the mug or a spoon is in the bowl." Coordination

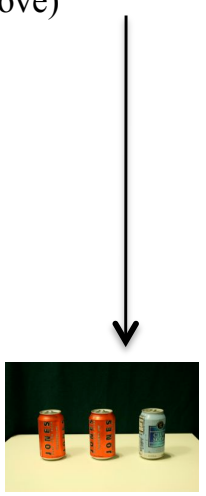

"All of the cans are red."

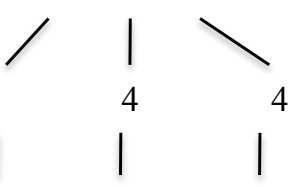

Match Test Mismatch (above)

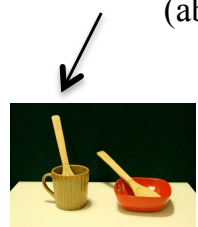

"A spoon is in the mug and a spoon is in the bowl."

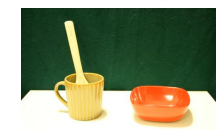

"A spoon is in the mug and a spoon is in the bowl."

Figure 7 Design of 24 experimental trials, shown in English: 12 Quantifier trials, 12 Coordination trials.

The description used in each trial was elicited by asking either the native signer (ASL) or native speaker (English) who produced the stimuli to view a scene on a laptop screen and describe what they saw using a given set of vocabulary and a basic sentence frame, with natural prosody. Each scene that they described appeared as the picture in some trial in the experiment. For example, to elicit All of the cans are red (English)/ CANS, ALL RED (ASL), the 
picture with all red cans was shown, and to elicit Some of the cans are red (English)/ CANS, SOME RED (ASL), the picture with only some of the cans being red was shown. In the Match trials the elicited description and picture were shown together, while in the Test and Mismatch trials the description was shown with the reverse picture. Thus, the conjunctive nonmanual marking was elicited by pictures where the conjunctive interpretation of COORD-SHIFT was true, and the disjunctive nonmanual marking was elicited by pictures where only one of the coordinates was true, i.e. a disjunctive interpretation was required.

\subsection{Results}

Results were analyzed using mixed logit models, which are well-suited for modeling data like the binary felicity judgements that the participants made in this study (Baayen 2007, Jaeger 2008). Unlike ANOVAs or t-tests, such models do not require normally distributed data. They also provide information about effect size for each factor in the magnitude of the coefficients $\beta$, eliminating the need for additional post-hoc tests.

Each participant's responses for each sentence type (quantifiers or coordination) and trial type (Match, Mismatch, Test) were considered, with language (ASL or English) fixed for each participant. Rejection (i.e. calculating the scalar implicature and rejecting the infelicitous description) was taken to be the "correct" response for the Test trial types. Acceptance was the correct Match response, rejection was the correct Mismatch response. In what follows, we first look separately at English participants' accuracy and at ASL participants' accuracy on different trials and scales to determine how their Test performance compares to performance on Match and Mismatch controls. Then, to ask whether scalar implicatures were computed, models are created of acceptances of Test trials (true but infelicitous) and Match trials (true and felicitous) in both languages, across scale types. Finally, we ask whether the coordination sentence type in ASL is different than the other scales (such as the quantifier scale in ASL and the coordination scale in English), building a model of all Test trials based on language and sentence type to determine if there is an interaction between these two languages and scales.

English A mixed logit model of all English response data with subject as a random effect and sentence type and trial type as fixed effects found 
'And' or 'or'

\begin{tabular}{llccc}
\hline & & Match & Mismatch & Test \\
\hline \multirow{2}{*}{ English } & Quantifiers & o & 1 & $0.77(0.38)$ \\
& Coordination & $0.02(0.07)$ & $0.92(0.16)$ & $0.77(0.36)$ \\
\hline \multirow{2}{*}{ ASL } & Quantifiers & $0.05(0.16)$ & $0.98(0.08)$ & $0.90(0.13)$ \\
\multirow{2}{*}{ Figure 8 } & Coordination & $0.20(0.20)$ & $0.83(0.17)$ & $0.35(0.21)$ \\
& Mean rejection rates (with standard deviations) for quantifiers and \\
& Coordination in English and in ASL. In the Test case, rejections \\
& indicate scalar implicature calculations. \\
\hline
\end{tabular}

no significant main effect of sentence type ( $\beta=15.72, z=0.01, p=0.99$ ), implying that for English the effects observed were the same for quantifiers as for coordinators. This model also found no interactions of sentence type and trial type and no significant difference between Match and Mismatch trials $(\beta=-1.48, z=-1.25, p=0.21)$. However, Test trials were significantly less likely to be answered correctly than the control Match or Mismatch trials $(\beta=-2.74, z=1.11, p=0.01)$. The decreased accuracy rates in the Test condition suggest a more flexible interpretation than either set of controls, which we could contribute to the fact that the cause for rejection is pragmatic instead of semantic.

Crucially, according to the pre-pragmatically strengthened reading both the Test and the Match conditions are true, and should be accepted. Under a scalar implicature reading, Test sentences will be rejected. Therefore, a mixed logit model was constructed of acceptances of the Test and Match trial types, with participant as a random factor and sentence type and trial type (Test and Match only) as fixed factors. In this model, Test trials were significantly less likely to be accepted than Match trials $(\beta=-6.15, z=-4.71, p<0.001)$, but there was no significant effect of sentence type $(\beta=15.72, z=0.01$, $p=0.99)$, and no interaction $(\beta=15.72, z=-0.01, p=0.99)$, suggesting that scalar implicature calculation was occurring in English, at the same rate for both the coordination and quantifier scales. In fact, English speakers correctly rejected the Test items in each sentence type at a rate of 0.77 , with a standard deviation of 0.36 for coordination and 0.38 for quantifiers (Figure $8)$. 
ASL A similar analysis was conducted with responses from the native signers of ASL. A mixed logit model was created of the all of the ASL participant data with participant as random effect and sentence type and trial type as fixed effects. This model found no significant main effect of sentence type ( $\beta=1.56, z=1.89, p=0.06)$, implying that, as in English, the effects observed were the same for quantifiers as for coordinators (crucially, this analysis includes all of the control Match and Mismatch trials, in addition to Test trials). Also as in English, there were no interactions of sentence type and trial type and no significant difference between Match and Mismatch trials ( $\beta=0.16, z=0.29, p=0.77$ ), but Test trial types were significantly less likely to be answered correctly $(\beta=-2.01, z=-3.89, p<0.001)$, which is again in line with a correct response requiring a pragmatic distinction, and not a semantic one.

To determine rate of scalar implicature calculation, we compare acceptances of Test and Match trial types in ASL, which under a pre-strengthened reading should both be true, as above for English. To this end, a mixed logit model of the acceptances in the Test and Match conditions was created with participant as a random effect and sentence type and trial type (Test and Match only) as fixed effects. In this model, there was no significant main effect of sentence type ( $\beta=1.56, z=1.89, p=0.06$ ) or trial type ( $\beta=-0.77$, $z=-1.49, p=0.14)$, but there was a significant interaction between the two $(\beta=-4.37, z=-4.23, p<0.001)$. The quantifier Test trials were appropriately rejected at a typical rate for scalar implicatures $(M=0.90$, $S D=0.13$ ), confirming results found from a separate group of signers on the same quantifier scale in ASL (Davidson 2011). The coordination scale, however, showed far fewer rejections in Test trials $(M=0.35, S D=0.21)$, suggesting that native ASL signers are not computing scalar implicatures in the same way for this sentence type. These results are striking, considering that within ASL the coordination and quantifier trials are both responses to the same trial type (the underinformative Test conditions) by the same set of native signers; nonetheless, there were fewer rejections (i.e. pragmatic strengthening) in the coordination scale in ASL. This suggests that the combination of COORD-SHIFT and disjunctive nonmanual marking is not enough to create the lexical contrast required for scalar implicature calculation.

Language/Scale Interaction We are also interested in the interaction between language and sentence type: how does the coordination scale in ASL pattern like the coordination scale in English? To this end, a mixed logit model was 
'And' or 'or'

created of all of the Test (i.e. the potential scalar implicature) responses with participant as a random effect and sentence type and language as fixed effects. In this model, there was a significant main effect of language with higher accuracy in English $(\beta=2.20, z=3.39, p<0.001)$, and a significant main effect of sentence type, with higher accuracy for the Quantifier scale $(\beta=3.15, z=4.70, p<0.001)$. Importantly, the interaction between language and sentence type was also significant $(\beta=-3.15, z=-3.72$, $p<0.001$ ), suggesting that not only is the coordination scale different within ASL, but it also doesn't pattern like the semantically similar coordination scale in English. Figure 9 presents a visual comparison of the Test trial results in both scales in ASL and English.

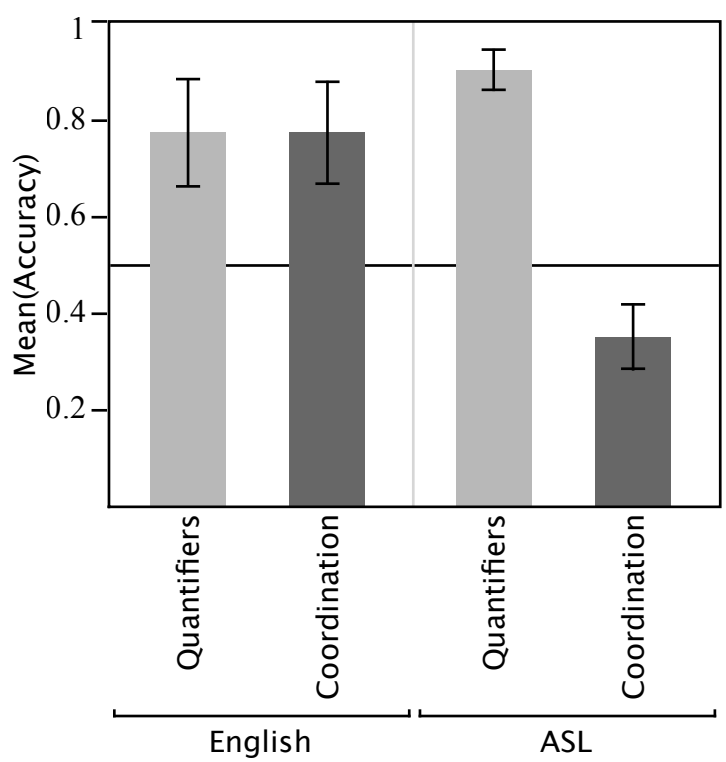

Figure 9 Calculation of implicatures (i.e. rejection rates) on quantifier and coordinator scales in ASL and English

Charitable Answering As a final note, recall that the general use coordinator can be interpreted as either disjunction or conjunction depending on the surrounding context. So, one explanation of the ASL coordination Test data presented so far could be that signers chose to interpret the coordinator in the most charitable way: they were accepting the Match sentences, but also the Test sentences, which had disjunctive nonmanual marking but which 
under a conjunctive interpretation would be felicitous. Here we can turn to the Mismatch data, where under a charitable interpretation the participants would be expected to accept the descriptions. Instead, what we find is that participants overwhelmingly reject the descriptions in the coordination Mismatch case $(M=0.83, S D=0.17)$, similar to the Match case $(M=$ $0.80, S D=0.20$ ). Recall that our model of ASL Test data above showed that rejections in the Test case $(M=0.35, S D=0.21)$ were significantly different from correct answers to Match and to Mismatch, although there was no difference between Match and Mismatch. We can conclude that while participants are not likely to reject Test trial descriptions, this is specific to underinformative descriptions not triggering a scalar implicature, and not due to an overall charitable answering strategy for coordination in ASL.

The results presented here suggest that the combination of COORD-shift and nonmanual marking (conjunctive and disjunctive) does not form a scale in the same way as lexically differentiated conjunction and disjunction like English and and or. According to Levinson 2000, to form a scale, scalemates need to be "in salient opposition: of the same form class, in the same dialect or register, and lexicalized to the same degree". As he says, this is to ensure that there should be no reason for choosing the weaker item on the scale other than the amount of information it conveys, because this is what causes the implicature that the stronger term is false to come about. In particular, for this reason the stronger term must be no more difficult to say than the weaker term (Matsumoto 1995), and no more syntactically complex (Katzir 2008). Disjunction and conjunction as expressed by a combination of general use coordination and nonmanual marking would seem to meet these criteria, and yet results suggest a lack of scalar implicatures. Thus, not only do we find support for the analysis against two separate lexical items advocated in Section 3, but this also suggests that Levinson's suggestion that scales be "lexicalized to the same degree" should encompass a distinction between manual signs and nonmanual marking in ASL, and potentially also a distinction between lexical items and intonational distinctions in spoken languages.

\section{Conclusion}

We have seen that one way to express conjunction and disjunction in ASL is to use general use coordination. As we saw in Section 2, general use coordinators in ASL have a syntactic distribution similar to English and and 
'And' or 'or'

or, but can be interpreted as either of those, depending on various other factors. General use coordination is not the only form of disjunction or conjunction in the language, although it is highly frequent. Furthermore, general use coordination comes in two forms in ASL: COORD-SHIFT, which involves small changes in location of the coordinates in the space in front of the signer, and COORD-L, which involves indexical points to successive fingers on the non-dominant hand before signed coordinates. In Section 3, I suggested a semantic analysis of general use coordination that allows their conjunctive and disjunctive uses to be disambiguated through quantification over the alternatives created by coORDs, with compositional rules based on Hamblin's alternative semantics. In Section 4, I investigated one aspect of the pragmatic interpretation of general use coordination by presenting a small study investigating the rate of scalar implicatures generated by the combination of the general use coordinator COORD-SHIFT and nonmanual marking. Results indicate that the addition of nonmanual marking to general use coordinators does not show the same pragmatic behavior as two lexical alternatives like English and and or.

Future research can determine how similar general use coordination in ASL is to general use coordinators in other languages, such as Maricopa and Japanese. A study comparing, for example, interpretations of juxtaposition in Japanese with coordinators in ASL is beyond the scope of this paper, but depending on how these coordinators interact with other forms in each language, we may expect to find similar results. Particularly in the area of scalar implicatures, which arise through what seem to be language-general mechanisms, we may expect to see a decrease in "exclusive disjunction" interpretations when juxtaposition is used in Japanese, even if the context makes it clear that there should be a disjunctive, not conjunctive, interpretation. Comparing different types of disjunction (both general use coordinators and other forms of disjunction, e.g. O-R in ASL and Japanese $\mathrm{ka}$ ) in each language would also be an important next step, although it is also beyond the scope of this paper. Yet another potential area of investigation among these languages concerns the ability of the coordinator to receive focus. Szabolcsi \& Haddican 2004 discuss the cross-linguistic generalization that languages which allow stress on coordinators (e.g. English) have a conjunctive/disjunctive ambiguity under negation that is absent in languages that do not allow stress on coordinators (e.g. Hungarian). Preliminary data suggests that general use coordinators in both ASL and Japanese fall into the Hungarian pattern both for focus and scopal interactions with negation (e.g. (43)-(44) above for ASL 
readings under negation). This is in line with the typological generalization, but surprising given that COORDs typically allow both readings. Further investigation is left to future research.

I conclude with a final note about the language modality. This paper focused on aspects of general use coordination that were unrelated to the fact that ASL is a sign language, because understanding the basic linguistic patterns of ASL as a natural language is often necessary before we attempt to understand the modality specific aspects. However, I hope that future research will have more to say about the role of three-dimensional space in COORD-L and COORD-SHIFT. There are good reasons to classify the two general use coordinators as different lexical items (COORD-L involves the nondominant hand and indexical points, while COORD-SHIFT involves changes in signing location), but it is also the case that they both make use of specific locations in space, or "loci" in ASL. It is an interesting question whether this is a coincidence, or a pattern of coordination more widely found in sign languages of the world. In ASL, the role of loci in a formal syntactic/semantic theory is an active topic of research, especially regarding the iconic aspects of loci (Schlenker, Lamberton \& Santori 2012) and how they related to pronominals and person marking more generally (Schlenker 2011, Lillo-Martin \& Meier 2011 and replies). It seems likely that as we continue to increase our understanding of this topic, there will be much more to say about space as used in COORD-L and COORD-SHIFT. On the other hand, we have seen that general use coordination can be found not only in ASL, but in some spoken languages like Maricopa and Japanese, and thus can tell us about properties relevant not only to the manual/visual sign language modality, but to natural language more generally.

\section{References}

Alonso-Ovalle, Luis. 2006. Disjunction in alternative semantics. Amherst, MA: University of Massachusetts $\mathrm{PhD}$ thesis.

Alonso-Ovalle, Luis. 2009. Counterfactuals, correlatives, and disjunction. Linguistics \& Philosophy 32(2). 207-244. http://dx.doi.org/10.1007/s10988oo9-9059-0.

Amritavalli, R. 2003. Question and negative polarity in the disjunction phrase. Syntax 6(1). 1-18. http://dx.doi.org/10.1111/1467-9612.00054.

AnderBois, Scott. 2011. Issues and alternatives. Santa Cruz, CA: University of California $\mathrm{PhD}$ thesis. 
'And' or 'or'

Baayen, R. Harald. 2007. Analyzing linguistic data: A practical introduction to statistics. Cambridge: Cambridge University Press.

Davidson, Kathryn. 2011. The nature of the semantic scale: Evidence from sign language research. San Diego, CA: University of California PhD thesis.

Deal, Amy Rose. 2011. Modals without scales. Language 87(3). 559-585. http: //dx.doi.org/10.1353/lan.2011.0060.

Fischer, Susan. 1996. By the numbers: Language-internal evidence for creolization. In William Edmondson \& Ronnie B. Wilbur (eds.), International review of sign linguistics: Volume 1, 1-22.

Fischer, Susan \& Diane Lillo-Martin. 1990. Understanding conjunctions. International Journal of Sign Linguistics 1(2). 71-80. http://www.haskins.yale. edu/Reprints/HLo832.pdf.

Gazdar, Gerald. 1979. Pragmatics: Implicatures, presupposition, and logical form. New York, NY: Academic Press.

van Gijn, I.C. 2004. The quest for syntactic dependency: Sequential complementation in Sign Language of Netherlands. University of Amsterdam PhD thesis.

Gil, David. 1991. Aristotle goes to Arizona and finds a language without 'and'. In Dietmar Zaefferer (ed.), Semantic universals and universal semantics, 96-130. Berlin: Foris Publications.

Grice, H. Paul. 1989. Studies in the way of words. Cambridge, MA: Harvard University Press.

Groenendijk, Jeroen. 2009. Inquisitive semantics: Two possibilities for disjunction. Logic, Language, and Computation 5422. 80-94. http://dx.doi. org/10.1007/978-3-642-00665-4_8.

Groenendijk, Jeroen \& Floris Roelofsen. 2009. Inquisitive semantics and pragmatics. Proceedings of the ILCLI International Workshop on Semantics, Pragmatics, and Rhetoric (SPR-o9). 41-72.

Hamblin, C.L. 1973. Questions in Montague English. Foundations of Language 10(1). 41-53. http://www.jstor.org/stable/25000703.

Haspelmath, Martin (ed.). 2004. Coordination constructions. Philadelphia, PA: John Benjamins.

Haspelmath, Martin. 2007. Coordination. In Timothy Shopen (ed.), Language typology and syntactic description, Vol. II: Complex constructions, 2nd edn., 1-51. Cambridge, MA: Cambridge University Press.

Hoeksema, Jack. 1988. The semantics of non-boolean and. Journal of Semantics 6. 19-40. http://dx.doi.org/10.1093/jos/6.1.19. 
Horn, Lawrence. 1989. A natural history of negation. Chicago, IL: Chicago University Press.

Jaeger, T. Florian. 2008. Categorical data analysis: Away from ANOVAs (transformation or not) and toward Logit Mixed Models. Journal of Memory and Language 59(4). 434-446. http://dx.doi.org/10.1016/j.jml.2007.11.007.

Janzen, Terry. 1999. The grammaticization of topics in american sign language. Studies in Language 23(2). http://dx.doi.org/10.1075/sl.23.2.03jan. Janzen, Terry \& B Shaffer. 2002. Gesture as the substrate in the process of asl grammaticization. In Richard P. Meier, Kearsy Cormier \& David QuintoPozos (eds.), Modality and structure in signed and spoken languages, 199223. Cambridge: Cambridge University Press.

Johnston, Trevor \& Adam Schlembri. 2007. Australian Sign Language: An introduction to sign language linguistics. Cambridge: Cambridge University Press.

Karttunen, Lauri. 1977. Syntax and semantics of questions. Linguistics \& Philosophy 1(1). 3-44. http://dx.doi.org/10.1007/BFo0351935.

Katzir, Roni. 2008. Structurally-defined alternatives. Linguistics \& Philosophy 30(6). 669-690. http://dx.doi.org/10.1007/s10988-008-9029-y.

Kratzer, Angelika \& Junko Shimoyama. 2002. Indeterminate pronouns: The view from Japanese. Proceedings of the Third Tokyo Conference on Psycholinguistics. 1-25. http://semanticsarchive.net/Archive/WEwNjc4Z/.

Levinson, Stephen. 200o. Presumptive meanings: The theory of generalized conversational implicature. Cambridge, MA: MIT Press.

Li, Charles \& Sandra Thompson. 1981. Mandarin Chinese: A functional reference grammar. Berkeley, CA: University of California Press.

Liddell, Scott. 1980. American Sign Language syntax. Mouton De Gruyter.

Liddell, Scott. 2003. Grammar, gesture, and meaning in American Sign Language. Cambridge: Cambridge University Press.

Lillo-Martin, Diane \& Richard P. Meier. 2011. On the linguistic status of 'agreement' in sign language. Theoretical Linguistics 37(3-4). 95-141. http://dx. doi.org/10.1515/thli.2011.oog.

Link, Godehard. 1983. The logical analysis of plurals and mass terms: A lattice theoretic approach. In Rainer Baeuerle, Christoph Schwarze \& Arnim von Stechow (eds.), Meaning, use, and interpretation. Berlin: de Gruyter.

Matsumoto, Yo. 1995. The conversational condition on Horn Scales. Linguistics \& Philosophy 18(1). 21-6o. http://dx.doi.org/10.1007/BFoog8496o. 
'And' or 'or'

Matthewson, Lisa. 2010. Cross-linguistic variation in modality systems: The role of mood. Semantics and Pragmatics 3(9). 1-74. http://dx.doi.org/10. 3765/sp.3.9.

Noveck, Ira A. 2001. When children are more logical than adults: Experimental investigations of scalar implicature. Cognition 78(2). 165-188. http://dx. doi.org/10.1016/Soo10-0277(oo)oo114-1.

Ohori, Toshio. 2004. Coordination in mentalese. In Martin Haspelmath (ed.), Coordinating constructions, 41-66. Amsterdam: John Benjamins Publishing Co.

Padden, Carol. 1988. Interaction of morphology and syntax in American Sign Language. San Diego, CA: University of California PhD thesis.

Papafragou, Anna \& Julien Musolino. 2003. Scalar implicatures: Experiments at the semantics-pragmatics interface. Cognition 86(3). 253-82. http://dx. doi.org/10.1016/Soo10-0277(02)00179-8.

Pfau, Roland \& Markus Steinbach. 2011. Grammaticalization in sign language. In Bernd Heine \& Heiko Narrog (eds.), Handbook of grammaticalization, 681-693. Oxford: Oxford University Press.

Rooth, Mats. 1992. A theory of focus interpretation. Natural Language Semantics 1(1). 75-116. http://dx.doi.org/10.1007/BF02342617.

Rullmann, Hotze, Lisa Matthewson \& Henry Davis. 2005. Modals as distributive indefinites. Natural Language Semantics 16(4). 1-41. http://dx.doi. org/10.1007/s11050-008-9036-o.

Sandler, Wendy. 2012. Visual prosody. In Roland Pfau, Markus Steinbach \& Bencie Woll (eds.), Sign language: An international handbook, 55-76. Berlin: De Gruyter Mouton.

Schlenker, Philippe. 2011. Donkey anaphora: The view from sign language (ASL and LSF). Linguistics \& Philosophy 34(4). 341-395. http://dx.doi.org/ 10.1007/s10988-011-9098-1.

Schlenker, Philippe, Jonathan Lamberton \& Mirko Santori. 2012. Iconic variables. Linguistics \& Philosophy. To appear.

Shaw, Emily \& Yves Delaport. 2010. New perspectives on the history of American Sign Language. Sign Language Studies 11(2). 158-204. http: //dx.doi.org/10.1353/sls.2010.0006.

Simons, Mandy. 2005. Semantics and pragmatics in the interpretation of $o r$. Semantics and Linguistic Theory (SALT) 15. http://elanguage.net/journals/ salt/article/view/15.205. 
Slabakova, Roumyana. 2010. Scalar implicatures in second language acquisition. Lingua 120(10). 2444-2462. http://dx.doi.org/10.1016/j.lingua.20o9. 06.005.

Szabolcsi, Anna \& Bill Haddican. 2004. Conjunction meets negation: A study in cross-linguistic variation. Journal of Semantics 21(3). 219-249. http: //dx.doi.org/10.1093/jos/21.3.219.

Vermeerbergen, Myriam, Lorraine Leeson \& Onno Crasborn (eds.). 2007. Simultaneity in signed languages. Amsterdam: John Benjamins.

Waters, Dafydd \& Rachel Sutton-Spence. 2005. Connectives in British Sign Language. Deaf Worlds 21(3).

Wilcox, Sherman. 2007. Routes from gesture to language. In Elena Pizzuto, Paola Pietrandrea \& Raffaele Simone (eds.), Verbal and signed languages: Comparing structures, constructs, and methodologies. Berlin: Mouton de Gruyter.

Wilcox, Sherman \& Barb Shaffer. 2006. Modality in ASL. In William Frawley (ed.), The expression of modality, 207-238. Berlin: Mouton de Gruyter. http://dx.doi.org/10.1515/9783110197570.207.

Winter, Yoad. 2007. Multiple coordination: meaning composition vs. the syntax-semantics interface. http://www.semanticsarchive.net/Archive/ jg2ZWIyO.

Kathryn Davidson

Program in Cognitive Science and Department of Linguistics

Yale University

P.O. Box 208366

New Haven, CT 06520-8366

kathryn.davidson@yale.edu 